Proceedings of the 31st Annual Meeting of the Brazilian Embryo Technology Society (SBTE); Cabo de Santo Agostinho, PE, Brazil, August 17th to 19th, 2017.

\title{
Reproductive programs for beef cattle: incorporating management and reproductive techniques for better fertility
}

\author{
José Luiz M. Vasconcelos ${ }^{1,4}$, Rafael Carvalho ${ }^{1}$, Rogério F.G. Peres ${ }^{1}$, Adnan D.P. Rodrigues ${ }^{1}$, \\ Izaias Claro Junior ${ }^{1}$, Mauro Meneghetti ${ }^{1}$, Fernando H. Aono ${ }^{1}$, Wedson M. Costa ${ }^{1}$, Catarina N. Lopes ${ }^{1}$, \\ Reinaldo F. Cooke ${ }^{2}$, Ky G. Pohler ${ }^{3}$
}

\author{
${ }^{1}$ São Paulo State University, Department of Animal Production, Botucatu, SP, Brazil. \\ ${ }^{2}$ Oregon State University, Eastern Oregon Agricultural Research Center, Burns, OR, USA. \\ ${ }^{3}$ Department of Animal Science, University of Tennessee, Knoxville, TN, USA.
}

\begin{abstract}
This review summarizes strategies to increase overall pregnancy rates to TAI protocols, and potential areas for improvement in reproductive management of Nelore cows. Low BCS at calving and postpartum BCS loss negatively impacted percentage of pregnant females to TAI, with primiparous cows being the most sensitive to the effects of low BCS during the postpartum period. The current reproductive management recommended for replacement heifers (with TAI on day 0) consist of intravaginal progesterone device insertion from day -35 to $-23,0.6 \mathrm{mg}$ i.m. injection of estradiol cypionate on day -23 , insertion of another intravaginal progesterone device and $2.0 \mathrm{mg}$ i.m. injection of estradiol benzoate on day $-11,12.5 \mathrm{mg}$ i.m. injection of dinoprost tromethamine on day -4 , intravaginal progesterone device removal and $0.6 \mathrm{mg}$ i.m. injection of estradiol cypionate on day -2 , and TAI on day 0 . Supplementing corn for 41 days after the first TAI of the breeding season increased pregnancy to a second $\mathrm{AI}$ in primiparous cows, increased final proportion of pregnancy in primiparous cows, but decreased the final proportion of pregnancy in mature cows. In turn, supplementing melengestrol acetate or $\mathrm{Ca}$ salts of PUFA during the expected time of luteolysis was beneficial to pregnancy rates. Vaccinating cows against BoHV-1, BVDV, and Leptospira spp., particularly when both doses were administered before TAI, improved cow reproductive performance. Cow temperament has direct implications not only on reproductive efficiency of $B$. indicus females, but also on overall production efficiency in cow-calf system based on B. indicus cattle. Lastly, concentration of pregnancy-associated glycoproteins was driven by the ability of pregnancy maintenance and by sire used at TAI, whereas exploring this relationship might be interesting to improve sire fertility regarding late embryonic loss in Nelore females.
\end{abstract}

Keywords: beef females, puberty, timed artificial insemination, Nelore, management strategies, reproduction.

\section{Introduction}

Hormonal treatments have been developed to synchronize the time of ovulation allowing fixed time artificial insemination (TAI) in anestrous or cycling cows, without the need for detection of estrus. The Group Specialized in Applied Herd Reproduction (Grupo Especializado em Reprodução Aplicada de Rebanho - GERAR (https://www.grupogerar.agr.br) was created in 2006 and composed primarily of veterinarians from all regions in Brazil that use the TAI protocol described by Meneghetti et al. (2009). The overall results of the GERAR are described in Fig. 1. This review summarizes some strategies that might increase overall pregnancy rates to TAI protocols, and also potential areas for improvement.

\section{Body condition score (BCS)}

The present study evaluated the effects of BCS at calving and postpartum BCS change on reproductive performance of suckled Nelore cows submitted to TAI ( Carvalho et al., 2017; UNESP, Department of Animal Production, Botucatu, SP, Brazil; unpublished data). A total of 1,909 cows were allocated based on age and days postpartum into 17 groups. All cows were submitted to a TAI protocol (Meneghetti et al., 2009) at approximately $38 \pm 2.4$ days postpartum (day 0 of the protocol). Pregnancy status were evaluated 30 days post-TAI. Cows were individually scored for body condition at calving, on the day of TAI, and 30 days post-TAI using a 1 to 5 scale with 0.25 increments $(1=$ thin to $5=$ fat $)$. Cows were divided into three groups according to BCS at calving: high $(\mathrm{H} ; \mathrm{BCS} \geq 3.5)$, moderate $(\mathrm{M} ; \mathrm{BCS}=$ 3.00 to 3.25$)$ and low $(\mathrm{L} ; \mathrm{BCS} \leq 2.75)$. Thereafter, cows were categorized into 1 of 7 groups based on $\mathrm{BCS}$ at calving and BCS change from calving to pregnancy diagnosis: high-maintaining (HM), highlosing (HL), moderate-gaining (MG), moderatemaintaining (MM), moderate-losing (ML), lowgaining (LG) and low-maintaining (LM). Low BCS at calving and postpartum BCS loss negatively impacted percentage of pregnant females to TAI, with primiparous cows being the most sensitive to the effects of low BCS during the postpartum period (Tables 1,2 and 3). 


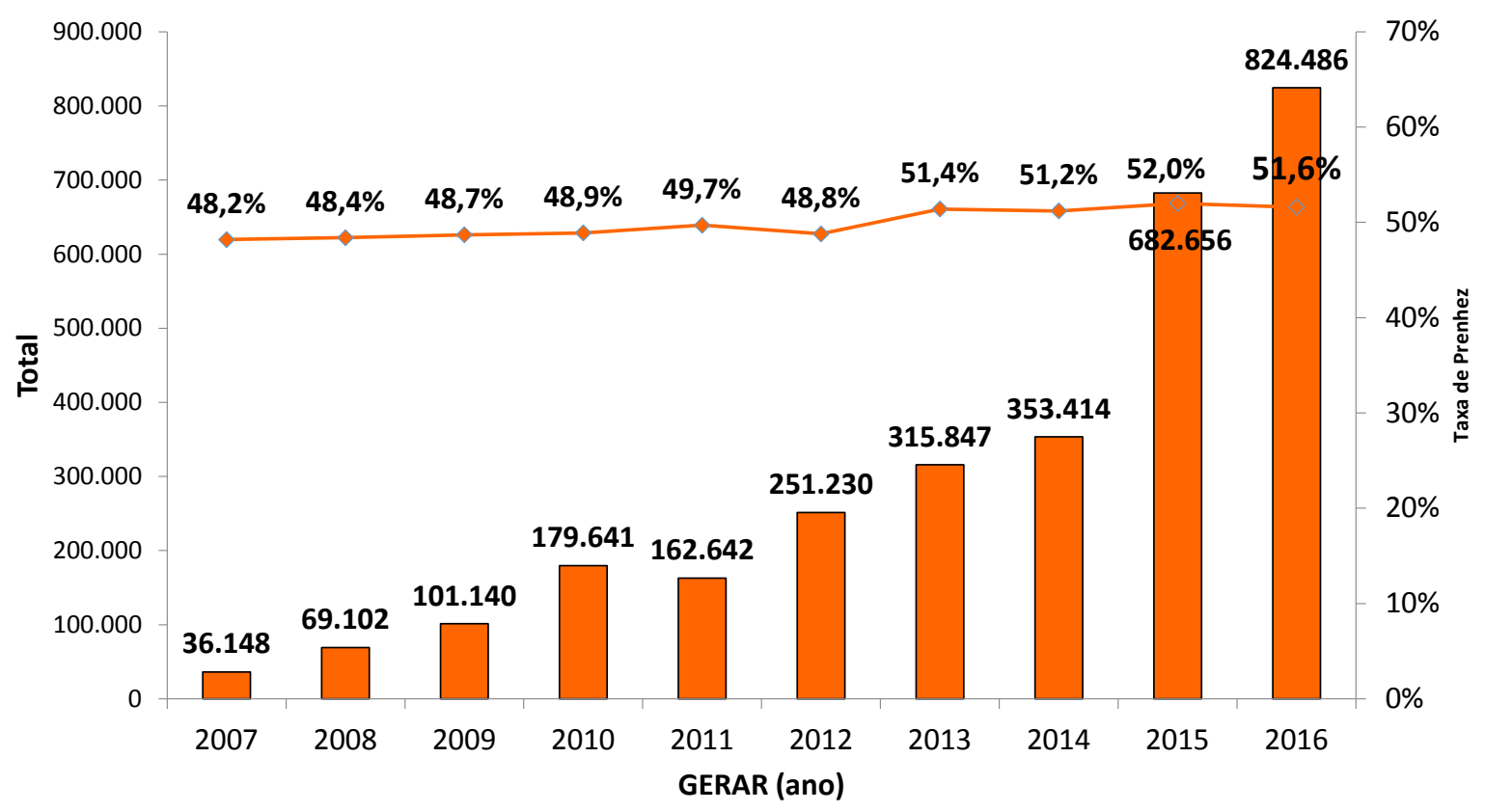

$\square$ Total $\multimap$ Taxa de Prenhez

Figure 1. Overall pregnancy to timed artificial insemination by year. Adapted from GERAR group.

Table 1. Effect of BCS at calving and BCS change from parturition to 80 days postpartum on pregnancies at first TAI $(\% \mathrm{P} / 1$ st AI) for primiparous suckled Nelore cows (total cows $=593)$.

\begin{tabular}{|c|c|c|c|c|c|c|}
\hline BCS at calving & Cows & $\% \operatorname{cows}^{1}$ & $\% \mathrm{P} / 1$ st AI & BCS Change & $\% \operatorname{cows}^{1}$ & $\% \mathrm{P} / 1 \mathrm{st} \mathrm{AI}$ \\
\hline $\operatorname{High}(\mathrm{H})$ & \multirow{2}{*}{142} & \multirow{2}{*}{23.9} & \multirow{2}{*}{$47.4^{\mathrm{a}}$} & Maintaining (HM) & 31.0 & $54.9^{\mathrm{a}}$ \\
\hline $\mathrm{BCS} \geq 3.5$ & & & & Losing (HL) & 69.0 & $43.0^{\mathrm{ab}}$ \\
\hline \multirow{3}{*}{$\begin{array}{l}\text { Moderate }(\mathrm{M}) \\
\mathrm{BCS}=3.00-3.25\end{array}$} & \multirow{3}{*}{358} & \multirow{3}{*}{60.4} & \multirow{3}{*}{$44.3^{\mathrm{a}}$} & Gaining (MG) & 25.7 & $54.5^{\mathrm{a}}$ \\
\hline & & & & Maintaining (MM) & 19.8 & $53.9^{\mathrm{a}}$ \\
\hline & & & & Losing (ML) & 54.5 & $35.7^{\mathrm{b}}$ \\
\hline Low (L) & \multirow{2}{*}{93} & \multirow{2}{*}{15.7} & \multirow{2}{*}{$25.9^{\mathrm{b}}$} & Gaining (LG) & 50.5 & $33.2^{\mathrm{bc}}$ \\
\hline $\mathrm{BCS} \leq 2.75$ & & & & Maintaining (LM) & 49.5 & $19.4^{\mathrm{c}}$ \\
\hline SEM & & & 4.4 & & & 6.0 \\
\hline P-value & & & 0.0023 & & & 0.0001 \\
\hline
\end{tabular}

${ }_{\mathrm{a}, \mathrm{b}, \mathrm{c}}$ Values within a column with different superscript letters differ at $\mathrm{P}<0.05 .{ }^{1} \%$ of cows according to BCS group at calving. From Carvalho et al., 2017; UNESP, Department of Animal Production, Botucatu, SP, Brazil; unpublished data.

Table 2. Effect of BCS at calving and BCS change from parturition to 80 days postpartum on pregnancies at first TAI $(\% \mathrm{P} / 1$ st $\mathrm{AI})$ for second parity suckled Nelore cows (total cows $=423)$.

\begin{tabular}{|c|c|c|c|c|c|c|}
\hline BCS at calving & cows & $\%$ cows & $\% \mathrm{P} / 1 \mathrm{st} \mathrm{AI}$ & BCS Change & $\% \operatorname{cows}^{1}$ & $\% \mathrm{P} / 1$ st AI \\
\hline $\begin{array}{l}\text { Moderate }(\mathrm{M}) \\
\text { BCS } 3.00-3.25\end{array}$ & 138 & 32.6 & $63.2^{\mathrm{a}}$ & $\begin{array}{l}\text { Gaining (MG) } \\
\text { Maintaining (MM) } \\
\text { Losing (ML) }\end{array}$ & $\begin{array}{l}29,0 \\
33,3 \\
37,7\end{array}$ & $\begin{array}{r}69.6^{\mathrm{a}} \\
68.0^{\mathrm{a}} \\
55.6^{\mathrm{ab}}\end{array}$ \\
\hline $\begin{array}{l}\text { Low BCS (L) } \\
\leq 2.75\end{array}$ & 285 & 67.4 & $41.4^{b}$ & $\begin{array}{l}\text { Gaining (LG) } \\
\text { Maintaining (LM) }\end{array}$ & $\begin{array}{l}53,3 \\
46,7\end{array}$ & $\begin{array}{l}45.6^{\mathrm{bc}} \\
35.7^{\mathrm{c}}\end{array}$ \\
\hline $\begin{array}{l}\text { SEM } \\
\text { P-value }\end{array}$ & & & $\begin{array}{c}6.8 \\
<0.0001\end{array}$ & & & $\begin{array}{c}8.3 \\
0.0002\end{array}$ \\
\hline
\end{tabular}

$\overline{\mathrm{a}, \mathrm{b}, \mathrm{c}}$ Values within a column with different superscript letters differ at $\mathrm{P}<0.05 .{ }^{1} \%$ of cows according to $\mathrm{BCS}$ group at calving. From Carvalho et al., 2017; UNESP, Department of Animal Production, Botucatu, SP, Brazil; unpublished data. 
Table 3. Effect of BCS at calving and BCS change from parturition to 80 days postpartum on pregnancies at first TAI $(\% \mathrm{P} / 1 \mathrm{st} \mathrm{AI})$ for multiparous suckled Nelore cows (total cows $=893)$.

\begin{tabular}{|c|c|c|c|c|c|c|}
\hline BCS at calving & cows & $\% \operatorname{cows}^{1}$ & $\% \mathrm{P} / 1 \mathrm{st} \mathrm{AI}$ & BCS Change & $\% \operatorname{cows}^{1}$ & $\% \mathrm{P} / 1$ st AI \\
\hline \multirow{2}{*}{$\begin{array}{l}\operatorname{High}(\mathrm{H}) \\
\mathrm{BCS} \geq 3.5\end{array}$} & \multirow{2}{*}{347} & \multirow{2}{*}{38.9} & \multirow{2}{*}{$57.5^{\mathrm{a}}$} & Maintaining (HM) & 40.6 & $59.9^{\mathrm{x}}$ \\
\hline & & & & Losing (HL) & 59.4 & $56.0^{\mathrm{xy}}$ \\
\hline \multirow{3}{*}{$\begin{array}{l}\text { Moderate }(\mathrm{M}) \mathrm{BCS}= \\
3.00-3.25\end{array}$} & \multirow{3}{*}{314} & \multirow{3}{*}{35.1} & \multirow{3}{*}{$51.4^{\mathrm{ab}}$} & Gaining (MG) & 20.1 & $62.6^{\mathrm{x}}$ \\
\hline & & & & Maintaining (MM) & 23.6 & $49.6^{\mathrm{xyz}}$ \\
\hline & & & & Losing (ML) & 56.4 & $48.1^{\mathrm{yz}}$ \\
\hline \multirow{2}{*}{$\begin{array}{l}\text { Low }(\mathrm{L}) \\
\mathrm{BCS} \leq 2.75\end{array}$} & \multirow{2}{*}{232} & \multirow{2}{*}{26.0} & \multirow{2}{*}{$45.9^{\mathrm{b}}$} & Gaining (LG) & 43.5 & $47.3^{\mathrm{yz}}$ \\
\hline & & & & Maintaining (LM) & 56.5 & $44.7^{z}$ \\
\hline SEM & & & 3.2 & & & 4.9 \\
\hline P-value & & & 0.0303 & & & 0.0718 \\
\hline
\end{tabular}

${ }^{\mathrm{a}, \mathrm{b}, \mathrm{c}}$ Values within a column with different superscript letters differ at $\mathrm{P}<0.05 .{ }^{\mathrm{x}, \mathrm{y}, \mathrm{z}}$ Values within a column with different superscript letters differ at $\mathrm{P}<0.1{ }^{1} \%$ of cows according to BCS group at calving. From Carvalho et al., 2017; UNESP, Department of Animal Production, Botucatu, SP, Brazil; unpublished data.

Meneghetti and Vasconcelos (2008) evaluated the association between BCS change during the pre and postpartum periods in beef heifers (Nelore and crossbred Nelore/Angus) bred to AI and calving from September to December in Brazil. The BCS were evaluated monthly during pre and post-partum periods (June to February). Heifers that calved earlier had greater $(\mathrm{P}<0.001)$ reduction on $\mathrm{BCS}$ (Fig. 2). In the Brazilian beef system, it is not beneficial to pregnancy to TAI for heifers to calve earlier, if the plan is to utilize TAI at the start of the next breeding season as primiparous cows. Heifers that calve earlier will become primiparous cows that lose more BCS during the postpartum period, and thus, experience decreased pregnancy rates to TAI. However, if these heifers calve later or closer to the actual time of AI, there is an increased chance of them becoming pregnant as a primiparous cow.
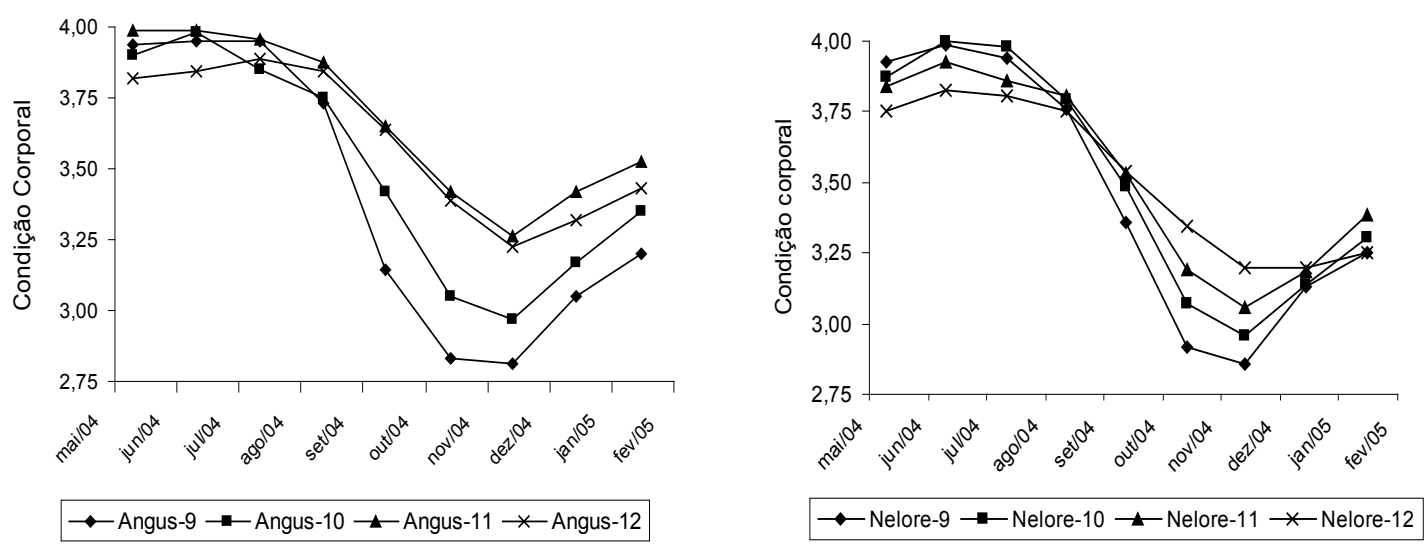

Figure 2. Body condition score change pre and post-partum in heifers (Nelore and $1 / 2$ Nelore $+1 / 2$ Red Angus) inseminated to calve from September to December.

\section{Puberty attainment}

Strategies to increase the number of pregnant beef heifers at the correct moment during the breeding season might affect the maintenance of these animals in the herd. The major factor that leads to failure in pregnancy in beef heifers during their first breeding season is the failure to attain puberty. Claro Junior et al. (2010) evaluated the use of intravaginal progesterone devices to induce puberty in Nelore prepubertal heifers. Heifers that received the intravaginal progesterone device had greater percentage of estrus detected, conception, and pregnancy rates compared to heifers that not treated with intravaginal progesterone device. Rodrigues et al. (2013) evaluated additional hormonal strategies to further increase puberty attainment in Nelore heifers assigned to the protocol proposed by Claro Junior et al. (2010). Rodrigues et al. (2013) concluded that the addition of $0.5 \mathrm{mg}$ of estradiol cypionate increased the percentage of Nelore heifers detected in estrus and that became pregnant. In another study, Rodrigues et al. (2014) evaluated the optimal interval to start a timed-AI protocol after the puberty induction protocol. Using a 12-day interval in relation to a 10-day interval resulted in greater pregnancy rates in Nelore heifers. Furthermore, the induction of puberty 
followed by TAI program proposed by Rodrigues et al. (2014) were evaluated in Nelore heifers regardless of their puberty status before the start of the study (Rodrigues et al., 2016). Pregnancy rates of heifers submitted to puberty induction protocol before the TAI program did not differ compared with pubertal heifers submitted only to a standard TAI protocol (Fig. 3). Therefore, it is not necessary to evaluate pre-breeding puberty status of Nelore heifers, and all heifers could be simultaneously assigned to the same estrus and ovulation synchronization protocol. The reproductive program indicated for heifers consisted of an intravaginal progesterone device insertion for 12 days (day -35 to day -23), $0.6 \mathrm{mg}$ i.m. injection of estradiol cypionate on day -23 , insertion of another intravaginal progesterone device and $2.0 \mathrm{mg}$ i.m. injection of estradiol benzoate on day -11 (beginning of the timed-
AI protocol), $12.5 \mathrm{mg}$ i.m. injection of dinoprost tromethamine on day -4 , intravaginal progesterone device removal and $0.6 \mathrm{mg}$ i.m. injection of estradiol cypionate on day -2 , and TAI on day 0 ( $48 \mathrm{~h}$ after device removal). With the inclusion of a puberty induction protocol before the TAI protocol (Rodrigues et al., 2014), heifers will be artificially inseminated about 30 days later than mature cows. Therefore, heifers will calve closer to the start of their subsequent breeding season and experience improved reproductive performance compared with heifers calving at earlier months. According to Meneghetti and Vasconcelos (2008), primiparous cows inseminated with a few days postpartum have greater BCS at TAI and more likely to become pregnant to TAI compared with primiparous cows with longer postpartum interval and smaller BCS at TAI.

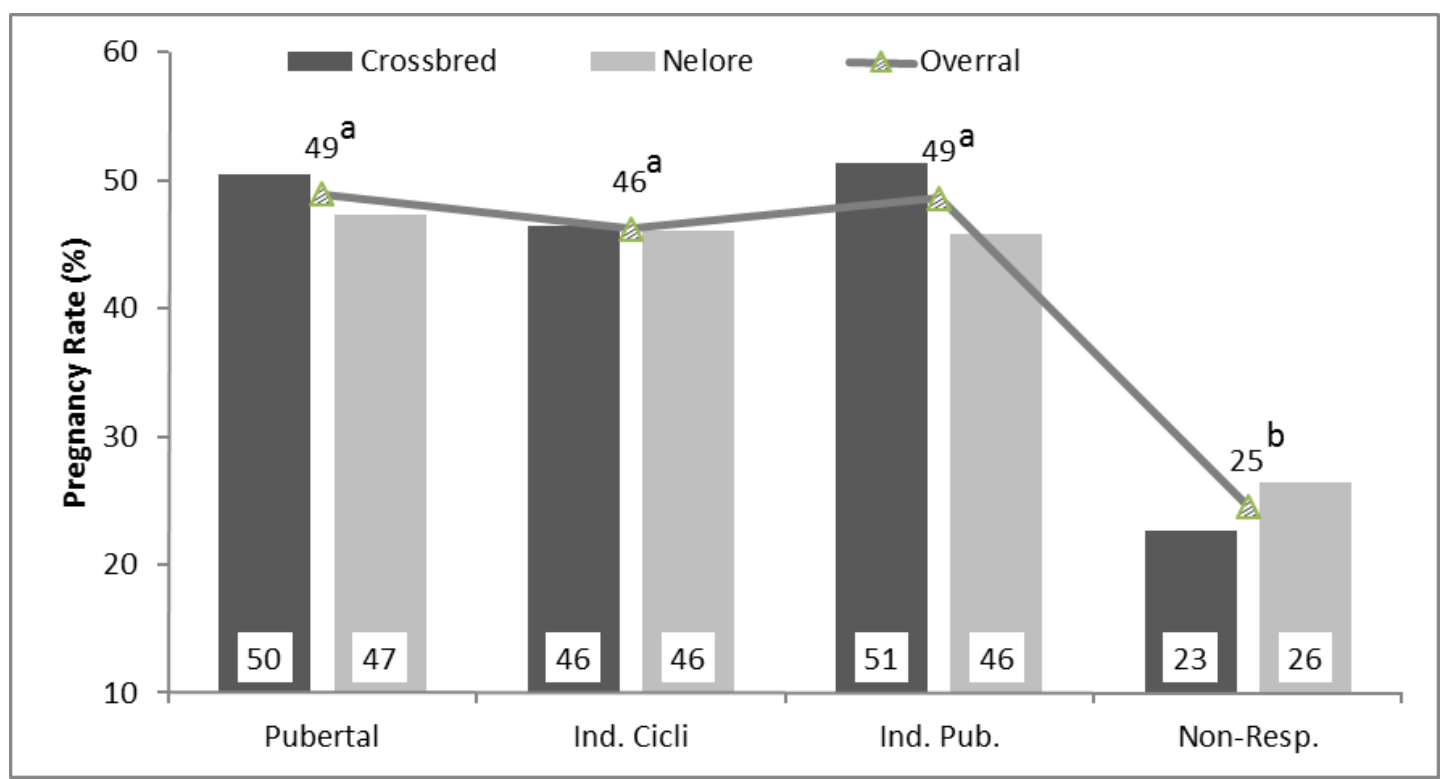

Figure 3. Overall pregnancy rates for the experimental groups: Pubertal $(n=967)$, induced cyclic heifers $(n=841)$, induced pre-pubertal heifers $(n=2,052)$ and non-responded pre-pubertal heifers $(n=1,424)$. Bars represent the experimental groups in each breed: Crossbred $(\mathrm{n}=380,102,957$ and 816) and Nelore $(\mathrm{n}=587,739,1,095$ and 608$)$ for pubertal, induced cyclic heifers, induced pre-pubertal heifers and non-responded pre-pubertal heifers, respectively

\section{Energy supplementation}

As suggested by Carvalho (2017; UNESP, Department of Animal Production, Botucatu, SP, Brazil; unpublished data), BCS loss could negatively affect the postpartum fertility of Nelore cows. A recent study by Peres et al. (2016) evaluated the effects of corn supplementation beginning at the start of a TAI protocol (day 0) until pregnancy diagnosis, $42 \mathrm{~d}$ later, on reproductive performance of Nelore females. In experiment 1, 1, 681 primiparous cows $(\mathrm{BCS}=2.84 \pm$ 0.36 and body weight $=407 \pm 42.6 \mathrm{~kg}$ ) were used. In experiment 2 , Nelore females $(\mathrm{n}=2,395)$ were divided into 20 groups that included heifers ( $\mathrm{n}=648 ; 4$ groups), primiparous $(\mathrm{n}=635 ; 6$ groups) and multiparous $(\mathrm{n}=$ 1,$112 ; 10$ groups), with an overall $\mathrm{BCS}=2.96 \pm 0.36$ and body weight $=401 \pm 50.1 \mathrm{~kg}$. All primiparous and multiparous cows were assigned to a resynchronization protocol and second TAI if they were diagnosed as nonpregnant on day 41. Calf weaning weight was evaluated in experiment 2. After calving, each group of cows was randomly assigned into two treatments, no corn supplementation (NS) or daily corn supplementation at $1.0 \mathrm{~kg} / \mathrm{cow}$ (as-fed basis) from day 0 to 11 (adaptation to supplementation), and $2.2 \mathrm{~kg} / \mathrm{cow}$ from day 11 to $41(\mathrm{CS})$. Both treatments reameind on pastures with free choice access to water and mineral supplementation. The TAI protocols started approximately 35 days after calving. In experiment, there was no difference $(\mathrm{P} \geq 0.17)$ on pregnancy to TAI (44.0 vs. 50.0\%), pregnancy to second TAI (36.0 vs. $40.0 \%$ ), and final proportion of pregnant cows $(67.5 \%)$ between NS and CS treatments, respectively. In experiment, there was no difference $(\mathrm{P}=0.50)$ in pregnancy per TAI between NS and CS cows (51.0 vs. 52.4\%, respectively), but mature cows had greater $(\mathrm{P}<0.01)$ pregnancy per TAI $(56.6 \%)$ compared with nulliparous $(48.0 \%)$ and primiparous cows $(50.5 \%)$. 
Cows with BCS below 2.75 on day 0 of the TAI protocol had less $(\mathrm{P}<0.01)$ pregnancy per TAI compared with cows with BCS 2.75 or more (44.1 vs. $55.5 \%)$. Pregnancy to the second TAI tended $(\mathrm{P}=0.10)$ to increase for CS vs. NS cows (44.3 vs. 38.5\%, respectively). Mature cows had greater $(\mathrm{P}=0.01)$ pregnancy to the second AI compared with primiparous cows (46.2 vs. 36.6\%). There was an interaction ( $\mathrm{P}<$ $0.01)$ between treatment and cow category: CS increased final proportion of pregnant cows in primiparous cows $(77.8$ vs. 65.7\%; $\mathrm{P}<0.05)$, but reduced that in mature cows (86.9 vs. 91.9\%; $\mathrm{P}<0.05)$, but had no effect on final proportion of pregnancy in nulliparous cows $(89.3 \% ; \mathrm{P}=0.37)$. Calves from primiparous cows that received corn supplementation were heavier $(\mathrm{P}<0.01)$ at weaning compared with calves from NS primiparous cows $(208 \pm 1.54$ vs. $195 \pm$ $1.73 \mathrm{~kg}$ ). Mature and primiparous cows that received CS $(425 \pm 2.36$ and $464 \pm 1.81 \mathrm{~kg})$ were heavier $(\mathrm{P}=0.01)$ at the end of the breeding season compared with NS mature and primiparous cows $(415 \pm 2.47$ and $458 \pm$ $1.84 \mathrm{~kg}$ ). In conclusion, corn supplementation for 41 days increased pregnancy to a second $\mathrm{AI}$ in primiparous and multiparous cows, increased final proportion of pregnancy in primiparous cows, but decreased the final proportion of pregnancy in mature cows despite the increased body weight of primiparous and multiparous cows at the end of the breeding season.

\section{Polyunsaturated fatty acids (PUFA) supplementation}

Another nutritional strategy that can improve pregnancy rates of beef cows is the supplementation of $\mathrm{Ca}$ salts of PUFA. Five experiments evaluated the effects of supplemental $\mathrm{Ca}$ salts of saturated fatty acids compared with $\mathrm{Ca}$ salts of unsatured fatty acids $(\mathrm{Ca}$ salts of PUFA) on reproductive function of Nelore cows (Lopes et al., 2009, 2011 ). In experiment 1, 51 nonlactating and multiparous grazing cows were assigned to receive (as-fed basis) $0.1 \mathrm{~kg} /$ day of a protein-mineral mix $+0.1 \mathrm{~kg}$ /day of ground corn, and $0.1 \mathrm{~kg}$ /day of: 1) Ca salts of PUFA (PF; Megalac-E, Quimica Geral do Nordeste, Rio de Janeiro, Brazil), 2) $\mathrm{Ca}$ salts of saturated fatty acids (SF; Megalac, Church and Dwight, Princeton, NJ), or 3) kaolin, a rumen-inert compound to equalize DM intake (control). Treatments were offered from day 0 to 20 of the estrous cycle. No treatment effects were detected on serum progesterone concentrations $(\mathrm{P}=0.83)$, day of luteolysis $(\mathrm{P}=0.86)$, or incidence of short cycles $(\mathrm{P}=0.84)$. In experiment 2 , 43 non-lactating, multiparous Nelore cows were assigned to receive $\mathrm{PF}, \mathrm{SF}$, or control from day 0 to 8 of the estrous cycle. On day 6 , all cows received $25 \mathrm{mg}$ i.m. injection of PGF $2 \alpha$. No treatment effects were detected on serum progesterone concentrations on day 6 $(\mathrm{P}=0.37)$, and incidence $(\mathrm{P}=0.67)$ or estimated time of luteolysis $(\mathrm{P}=0.44)$. In experiment 3,27 lactating, multiparous Nelore cows were assigned to receive daily supplementation of PF or Control for 10 days, beginning at the first postpartum ovulation (30 to 40 days postpartum). No treatment effects were detected ( $\mathrm{P}$ $=0.85)$ for incidence of short cycles. In experiment 4 ,
1,454 lactating, multiparous Nelore cows were assigned to receive 1 of the 7 treatments for 28 days after TAI (day $0 ; 40$ to 60 days postpartum): 1) control from day 0 to $28 ; 2$ ) SF from day 0 to 14 and control from day 14 to $28 ; 3)$ PF from day 0 to 14 and then control from day 14 to $28 ; 4)$ SF from day 0 to 21 and then control from day 21 to 28 ; 5) $\mathrm{PF}$ from day 0 to 21 and then control from day 21 to 28 ; 6) SF from day 0 to 28 ; and 7) PF from day 0 to 28 . Cows receiving daily PF supplementation for more than 21 days after TAI had greater $(\mathrm{P}<0.01)$ pregnancy to TAI compared with all other treatments combined (50.4 vs. $42.4 \%$, respectively). In experiment 5, 501 lactating, multiparous Nelore cows were assigned to receive 1 of the 4 treatments for 21 days after TAI (day $0 ; 40$ to $60 \mathrm{~d}$ postpartum): 1) PF from day 0 to 14 and control from day 14 to 21,2 ) control from day 0 to 6 and PF from day 6 to $21 ; 3$ ) control from day 0 to 13 and PF from day 14 to 21 ; and 4) PF from day 0 to 21 . Cows receiving $\mathrm{PF}$ after day 14 had greater $(\mathrm{P}=0.02)$ pregnancy rate to TAI compared to cows not receiving PF during the same period (46.8 vs. $33.1 \%$, respectively). In summary, supplemental $\mathrm{Ca}$ salts of PUFA during the expected time of luteolysis increased pregnancy to TAI in Nelore cows.

\section{Vaccination against reproductive diseases}

Decrease pregnancy losses could increase the proportion of cows calving at the beginning of the calving season. The objectives of the experiments described below were to assess the incidence of pregnancy loss, associate this outcome with immunization programs against reproductive diseases, and evaluate the effects of vaccination against bovine herpesvirus-1 (BoHV-1), bovine viral diarrhea virus (BVDV), and Leptospira spp., on reproductive efficiency of commercial cow-calf operations (Aono et al., 2013). In study 1, 7614 lactating Nelore cows from 18 cow-calf operations were assigned to the same estrous synchronization + TAI protocol (Meneghetti et al., 2009). Pregnancy status was determined with transrectal ultrasonography on days 30 and 120 after TAI. Pregnancy loss was defined as cows that were diagnosed as pregnant on day 30 , but non-pregnant on day 120 . Incidence of pregnancy loss across all ranches was $4.1 \%$; pregnancy losses were detected in 14 operations, but not detected in four operations. Pregnancy loss was less $(\mathrm{P} \leq 0.02)$ in farms using vaccination against BoHV-1, BVDV, and Leptospira spp. compared with farms that did not use vaccination, or only vaccinated against Leptospira spp. In experiments 2 and 3, lactating Nelore cows ( $\mathrm{n}=950$ and 793, respectively) from operations that did not have a history of vaccinating against reproductive diseases (experiment 2), or only vaccinated against Leptospira spp. (experiment 3), were assigned to the same TAI protocol used in study 1 . Within each operation, cows received vaccination against BoHV-1, BVDV, and Leptospira spp. at the beginning of the TAI protocol (day -11) and 30 days after TAI (day 41; VAC) or remained as unvaccinated controls (control). In experiment 2, VAC cows had greater $(\mathrm{P} \leq 0.05)$ 
pregnancy rates compared with control cows on days 30 and 120 (Table 4). In experiments 2 and 3, pregnancy loss was reduced $(\mathrm{P} \leq 0.03)$ in primiparous VAC compared with control cohorts. In experiment 4, 367 primiparous, lactating Nelore cows previously vaccinated against Leptospira spp. were assigned to received the vaccine at the beginning (VAC) of the TAI protocol (day -11) and 30 days after TAI (day 41) or at 30 days prior to (day -41) and at the beginning (day -11) of the TAI protocol (PREVAC). Pregnancy rates on days 30 and 120 were greater $(\mathrm{P} \leq 0.05)$ in PREVAC cows compared with VAC cows. In conclusion, pregnancy losses impacted reproductive performance of beef cows and may be associated with BoHV-1, BVDV, and Leptospira spp. infections. Hence, vaccinating cows against these pathogens, particularly when both doses are administered before TAI, improved reproductive performance.

Table 4. Pregnancy rates 30 and 120 days after fixed-time AI in cows from experiments 2,3 , and $4^{1}$.

\begin{tabular}{lll}
\hline \multicolumn{1}{c}{ Experiment $^{2}$} & \multicolumn{1}{c}{ 30 days } & Pregnancy status $^{3}$ \\
\hline Experiment 2 & \multicolumn{1}{c}{120} \\
VAC & $55.1(546 / 935)$ & $53.5(532 / 935)$ \\
COM & $49.8(548 / 1015)$ & $45.9(523 / 1015)$ \\
SEM & 2.8 & 2.8 \\
P-Value & 0.05 & 0.01 \\
& & \\
Experiment 3 & & $46.8(579 / 1292)$ \\
VAC & $47.3(599 / 1292)$ & $44.7(692 / 1501)$ \\
COM & $46.7(726 / 1501)$ & 4.9 \\
SEM & 4.8 & 0.45 \\
P-Value & 0.84 & \\
Experiment 4 & & $54.7(127 / 232)$ \\
PREVAC & $55.6(129 / 232)$ & $42.9(58 / 135)$ \\
VAC & $45.2(61 / 135)$ & 3.8 \\
SEM & 3.8 & 0.03 \\
P-Value & 0.05 &
\end{tabular}

${ }^{1}$ Pregnancy rates to fixed-time AI are reported as least square means. Values in parentheses represent number of pregnant cows/total inseminated cows. ${ }^{2}$ In experiment 2 and 3, cows received (VAC) or not (CON) vaccination against IBR, BVD, and leptospirosis on day -11 and day 30 relative to fixed-time AI (day 0 ). In experiment 4 , cows received vaccination against IBR, BVD, and leptospirosis (at two different schedules relative to fixed-time AI (day $0)$ : 1) day -41 and day -11 (PREVAC), or 2) day -11 and day 30 (VAC =135). In experiment 3 and 4, cows already received biannual vaccination against leptospirosis. ${ }^{3}$ Pregnancy status was verified by detecting a fetus with transrectal ultrasonography at 30 and 120 days after fixed-time AI.

\section{Melengerol acetate (MGA) supplementation}

Another strategy to increase the proportion of cows calving at the beginning of the calving season is MGA supplementation after TAI. This experiment compared pregnancy rates in Bos indicus cows assigned to temporary calf weaning (TCW) or eCG administration during estrus synchronization, and receiving or not MGA supplementation after AI (Costa et al., 2015). A total of 3,042 lactating, multiparous, nonpregnant Nelore cows were managed in 48 groups, and assigned to an estrous synchronization + TAI protocol (day -11 to 0 ). On day -11 , groups were randomly assigned, in a $2 \times 3$ factorial arrangement of treatments, to receive 1 of 2 gonadotropic stimulus: 48 -h TCW from day -2 to AI on day $0(n=9$ groups, 604 cows) or 300 IU i.m. injection of eCG on day -2 (n $=39$ groups, 2438 cows). Then, on day 1 , groups were assigned to receive 1 of 3 MGA treatments: 1) $0.5 \mathrm{mg}$ of MGA/cow from day 5 to 18 (M5-18; $\mathrm{n}=16$ groups, 1074 cows) or from day 13 to $18(\mathrm{M} 13-18 ; \mathrm{n}=16$ groups, 971 cows), or no MGA supplementation (CON; $\mathrm{n}=16$ groups, 997 cows). Estrus expression was evaluated by painting the tailhead of each cow on day -2 , and verifying if paint completely disappeared at TAI. Body condition score (1 to 9 scale) was evaluated at TAI, and cows were classified as having adequate $(24.5)$ or inadequate $(<4.5)$ BCS. Pregnancy rates on days 30 and 80 were greater $(\mathrm{P} \leq 0.05)$ in $\mathrm{M} 5$ 18 and M13-18 compared to $\mathrm{CON}$ cows, and were similar $(\mathrm{P} \geq 0.79)$ among $\mathrm{M} 5-18$ and M13-18 (Table 5). The MGA supplementation $\times$ gonadotropic stimulus interaction was not detected $(\mathrm{P} \geq 0.41)$, whereas no interactions of main effects with cow BCS and estrus expression were detected $(\mathrm{P} \geq 0.21)$ for pregnancy outcomes. Supplementing Nelore beef cows with MGA post-AI increased pregnancy rates compared with non-supplemented cows, and this outcome was independent of period and length of MGA supplementation, gonadotropic stimulus, cow BCS status, and estrus expression during the synchronization protocol. 


\section{Q6.}

Table 5. Pregnancy outcomes in Bos indicus beef cows assigned to different gonadotropic stimulus (eCG administration or temporary calf weaning (TCW)] and receiving or not melengerol acetate (MGA) supplementation after fixed-time AI.

MGA supplementation ${ }^{1}$

\begin{tabular}{|c|c|c|c|c|c|c|c|c|}
\hline Item & TCW & eCG & $\mathrm{P}=$ & $\mathrm{COM}$ & M5to18 & M13to18 & SEM & $\mathrm{P}=$ \\
\hline \multicolumn{9}{|l|}{ Pregnant, ${ }^{3} \%$} \\
\hline day 30 & $62.6(384 / 604)$ & $58.1(1432 / 2438)$ & 0.17 & $55.3^{\mathrm{a}}(554 / 997)$ & $62.9^{\mathrm{b}}(648 / 1074)$ & $62.9^{\mathrm{b}}(614 / 971)$ & 2.8 & 0.05 \\
\hline day 80 & $57.6(348 / 604)$ & $54.3(1349 / 2438)$ & 0.40 & $50.5^{\mathrm{a}}(513 / 997)$ & $58.1^{\mathrm{b}}(604 / 1074)$ & $59.2^{\mathrm{b}}(580 / 971)$ & 3.4 & 0.10 \\
\hline Pregnancy loss, ${ }^{4} \%$ & $9.4(36 / 384)$ & $6.8(83 / 1432)$ & 0.29 & $9.6(41 / 554)$ & $8.3(44 / 648)$ & $6.4(34 / 614)$ & 2.0 & 0.54 \\
\hline
\end{tabular}

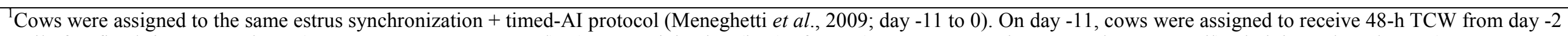

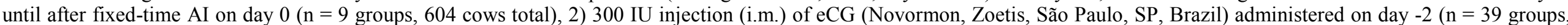

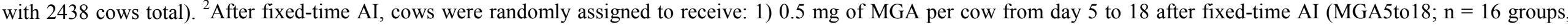

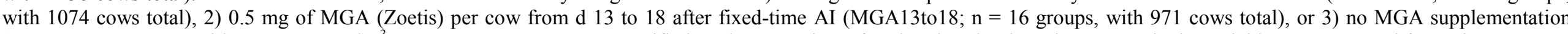

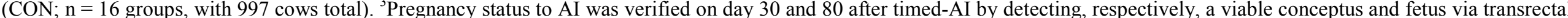

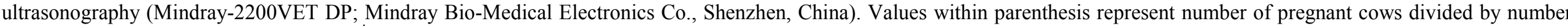

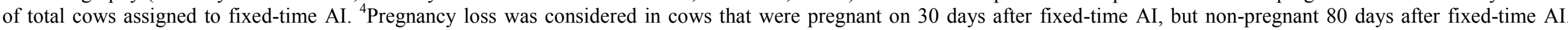
Values within parenthesis represent number of cows that lost AI pregnancy divided by number of diagnosed as pregnant 30 days after AI. 


\section{Cattle temperament}

Research has shown that behavioral and physiological responses associated with excitable temperament are detrimental to reproductive efficiency of B. taurus beef cows (Cooke, 2014), independently if cows are assigned to insemination by natural service or TAI protocols. Excitable temperament is detected more frequently in B. indicus cattle compared with B. taurus and B. taurus-crosses (Cooke, 2014). Therefore, cattle temperament might be of even greater importance for reproductive efficiency of cow-calf operations based on $B$. indicus cows, such as the cow-calf industry in Brazil. To address this subject, Cooke et al. (2011) assessed the effects of temperament on reproductive performance of Nelore females by associating temperament characteristics and pregnancy rates to TAI in Brazilian cow-calf operations. Were evaluated 761 multiparous cows from 4 different commercial cow-calf ranches for temperament when cows were processed for TAI (protocol described by Meneghetti et al., 2009). Temperament was assessed by chute score and exit velocity. Chute score was assessed by a single technician, immediately before TAI, based on a 5-point scale where: $1=$ calm with no movement, $2=$ restless movements, 3 = frequent movement with vocalization, 4 $=$ constant movement, vocalization, shaking of the chute, and $5=$ violent and continuous struggling. Exit velocity was assessed immediately after TAI by determining the speed of the cow exiting the squeeze chute by measuring rate of travel over a 1.9 -m distance. Further, within each ranch group, cows were divided in quintiles according to their exit velocity, and assigned a score from 1 to 5 (exit score; $1=$ cows within the slowest quintile; $5=$ cows within the fastest quintile). Individual temperament scores were calculated by averaging cow chute score and exit score. Cows were also classified according to the final temperament score (temperament type) as adequate temperament (temperament score $\leq 3$ ) or excitable temperament (temperament score $>3$ ).

Cooke et al. (2011) reported that pregnancy to TAI tended $(\mathrm{P}=0.08)$ to be negatively affected by temperament score (Fig. 4). The probability of cows becoming pregnant to TAI was negatively associated with temperament score (linear effect). Accordingly, pregnancy rates were reduced $(\mathrm{P}=0.05)$ in cows with excitable temperament compared to cows with adequate temperament (35.3 vs. $42.8 \%$ of pregnant cows/total cows, respectively). These results demonstrated that excitable temperament was detrimental to pregnancy to TAI in $B$. indicus beef cows, likely by stimulating, during handling for TAI, neuroendocrine stress responses that directly impair physiological mechanisms required for fertility in females. In fact, pregnancy rates were reduced by $17 \%$ when comparing cows with excitable temperament and cows with adequate temperament (35.3\% divided by 42.8$)$, or by $43 \%$ when comparing cows with the highest temperament score with those with the lowest temperament score $(29.3 \%$ divided by $51.4 \%$ for temperament score 4.5 and 1 , respectively). Based on these outcomes, we concluded that temperament has a significant impact on reproductive performance of $B$. indicus cows exposed to TAI protocols, whereas strategies to ameliorate temperament or the cowherd (such as selecting cattle for adequate temperament or encouraging interaction between young cattle and humans) are necessary to optimize reproductive and overall efficiency of Brazilian cow-calf operations. A follow-up experiment was conducted to further comprehend the impacts of temperament on productive and reproductive outcomes in B. indicus cowherds, including reproductive and overall productivity in females following a typical TAI + bull breeding season, calving season, and at offspring weaning (Cooke et al., 2017). In this experiment, temperament was evaluated in 953 multiparous Nelore cows at the time of TAI as in Cooke et al. (2011). Cows not pregnant to first TAI were assigned to a second TAI protocol or to bulls for 60 days. Cows with excitable temperament had greater $(\mathrm{P}<0.01)$ serum cortisol concentrations at TAI, reduced $(\mathrm{P}=0.09)$ pregnancy rate to first TAI, greater $(\mathrm{P}=0.05)$ pregnancy loss, reduced $(\mathrm{P}=0.04)$ calving rate, as well as reduced ( $\mathrm{P}$ $=0.09$ ) weaning rate compared with cows with adequate temperament (Table 6). Moreover, calves born from cows with excitable temperament were lighter and younger at weaning $(\mathrm{P} \leq 0.05)$ compared with calves from cows with adequate temperament (Table 6); hence, $\mathrm{kg}$ of calf weaned/cow exposed to breeding was reduced $(\mathrm{P}=0.04)$ in cows with excitable temperament (Table 6). Based on these outcomes, this experiment demonstrated that cattle temperament has direct implications not only on reproductive efficiency of $B$. indicus females, but also on overall production efficiency in cow-calf system based on $B$. indicus cattle. 


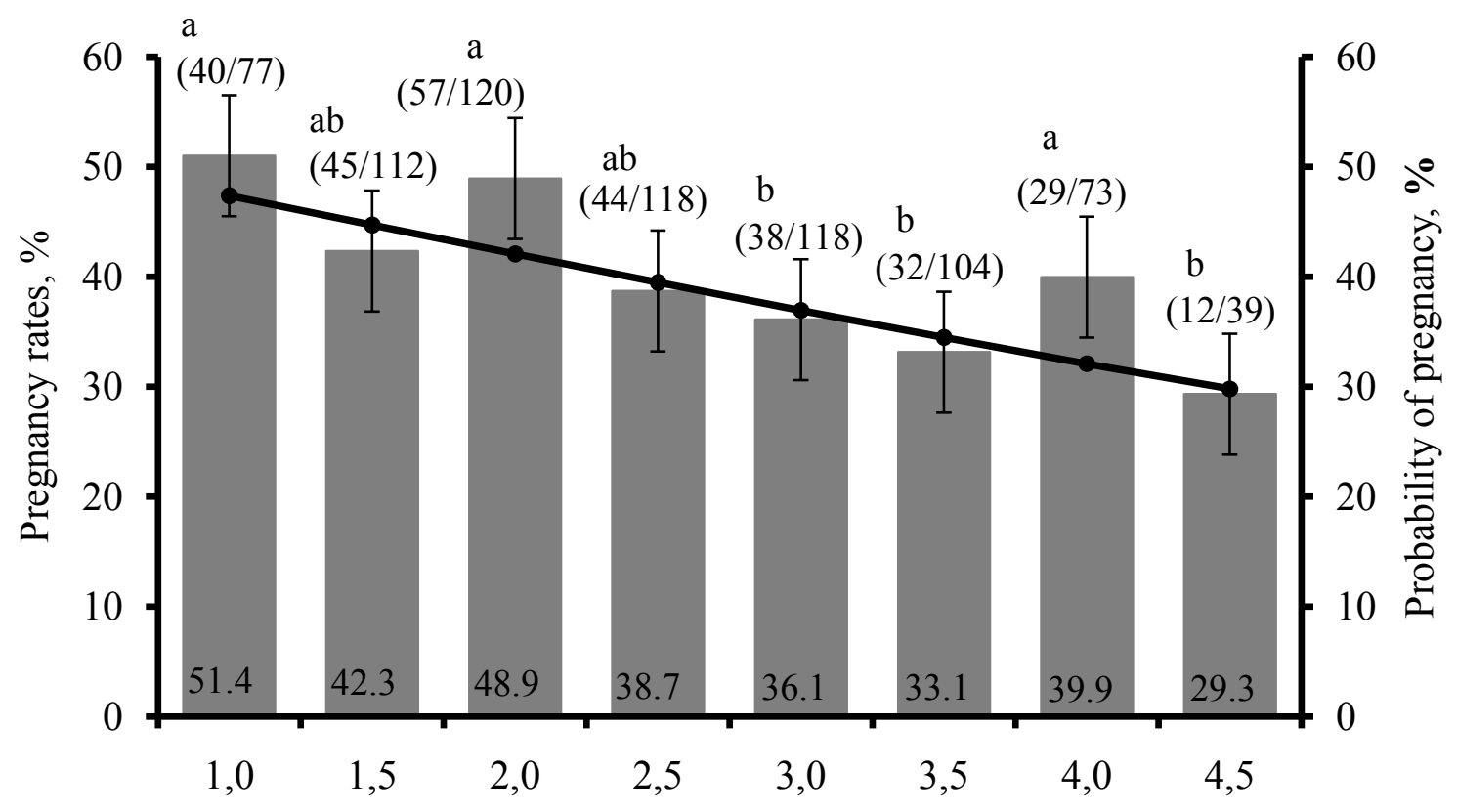

Temperament score

Figure 4. Pregnancy rates (bars) and probability of pregnancy (line) to TAI in Nelore (B. indicus) beef cows according to temperament score. Pregnancy rates tended $(P=0.08)$ to be negatively affected whereas probability of pregnancy was negatively associated (linear effect, $\mathrm{P}<0.01$ ) with temperament score. Values within bars correspond to means. Values in parenthesis correspond to pregnant cows divided by total cows assigned to the AI protocol. Means with different superscripts (a $v s$. b) differ at $\mathrm{P}<0.05$. Adapted from Cooke $e t$ al. (2011).

Table 6. Serum cortisol concentrations and overall productive responses of Nelore (Bos indicus) beef cows according to temperament evaluated at fixed-time AI.

\begin{tabular}{lcccc}
\hline & \multicolumn{2}{c}{ Temperament type $^{1}$} & & \\
\cline { 2 - 3 } Item & Adequate & Excitable & SEM & $\mathrm{P}=$ \\
\hline Physiological responses & & & & \\
$\quad$ Serum cortisol, ng/ml & 39.1 & 49.1 & 1.0 & $<0.01$ \\
Reproductive responses & & & & \\
$\quad$ Pregnancy rates, \% & & & & \\
$\quad$ First TAI & 47.3 & 41.0 & 3.6 & 0.09 \\
$\quad$ Second TAI & 43.1 & 39.2 & 5.1 & 0.56 \\
$\quad$ Natural breeding & $58.4(157 / 269)$ & $54.4(49 / 90)$ & 4.1 & 0.52 \\
$\quad$ Final (TAI + natural) & $79.5(577 / 726)$ & $75.8(172 / 227)$ & 2.1 & 0.23 \\
Calving rate, \% & $74.8(543 / 726)$ & $68.3(155 / 227)$ & 2.2 & 0.04 \\
Pregnancy loss, \% & $5.9(34 / 577)$ & $9.9(17 / 172)$ & 1.4 & 0.05 \\
& & & & \\
Calf parameters & & & & \\
Calf weaning age, d & 212 & 209 & 1 & 0.05 \\
Calf weaning BW, kg & 210 & & 2 & 0.04 \\
& & & & \\
Cow-calf production parameters & & & & \\
Calf loss from birth to weaning, \% & $7.2(39 / 543)$ & $6.4(10 / 155)$ & 1.5 & 0.75 \\
Weaning rate, \% & $69.4(504 / 726)$ & $63.9(145 / 227)$ & 2.4 & 0.09 \\
$\quad$ Kg of calf weaned per cow exposed, kg & 146 & 130 & 5 & 0.04 \\
\hline
\end{tabular}

${ }^{\top}$ Values within parenthesis represent positive responses (pregnant cows, cows that gave birth to a calf, cows that lost pregnancy, number of dead calves, or number of calves weaned) divided by cows exposed to breeding (or total calves born for calf loss results only). Adapted from Cooke et al. (2016).

\section{Sire fertility}

The variation in pregnancy to TAI caused by sire fertility is substantial (Table 7). Understanding the causes that affect conception and maintenance of pregnancy is fundamental to developing management 
strategies to increase fertility. Placental insufficiency is a cause of embryonic mortality (evaluated from days 30 to 100 of gestation) and bovine pregnancyassociated glycoproteins (PAG) have been used as a marker of placental function. Although the functional role of PAG is unclear, it has been shown that many factors affect PAG concentrations including pregnancy stage, breed, parity, sire and fetal sex. Limited data have been reported on sire effects on PAG concentration, however, based on the influence sire has on placental development, we were interested in this potential relationship. A previous study from our group pointed toward a relationship between bull fertility/pregnancy loss and circulating concentrations of PAG in early gestation in postpartum Nelore cows (Pohler et al., 2016). Thus the objectives of this study were to determine how sire used for TAI influences embryonic loss rate and PAG concentration at day 30. Postpartum Nelore beef cows $(n=736)$ were artificially inseminated using 6 Angus sires at a fixed time (day 0) after synchronization of ovulation (Franco et al., 2017; unpublished data). Pregnancy diagnosis by ultrasound was performed and serum samples were collected on day 30. Serum concentrations of PAG were quantified using an in house PAG ELISA with antibodies raised against PAGs expressed early in gestation. Overall pregnancy rate at day 30 was $53.75 \%$ and late embryonic loss was $6.21 \%$. Mean concentration of PAGs of pregnant cows at day 30 was $8.81 \pm 0.24$ $\mathrm{ng} / \mathrm{ml}$, and cows that maintained a pregnancy from days 30 to 100 of gestations had significantly $(P=0.004)$ greater serum concentrations of $\mathrm{PAG}$ on day 30 compared with cows that did not maintain a pregnancy until day $100(8.98 \pm 0.25$ vs. $5.95 \pm 1.02 \mathrm{ng} / \mathrm{ml})$. Although there was variation in sire conception rate to TAI, there was no linear relationship between sire pregnancy rate and circulating concentrations of PAGs (Sire $1=51.56 \%, 7.72 \mathrm{ng} / \mathrm{ml}$; Sire $2=49.17 \%, 8.96$ $\mathrm{ng} / \mathrm{ml}$; Sire $3=55.28 \%, 8.81 \mathrm{ng} / \mathrm{ml}$; Sire $4=55.28 \%$, $10.14 \mathrm{ng} / \mathrm{ml}$; Sire $5=55.28 \%, 8.42 \mathrm{ng} / \mathrm{ml}$, and Sire $6=$ $35.29 \%, 9.52 \mathrm{ng} / \mathrm{ml})$. Then, sires were classified according to percentage on total embryonic mortality between days 30 and 100 as high embryonic loss (Sire 1 $=20 \%$; Sire $2=28 \%$, and Sire $3=24 \%$ ) or low embryonic loss (Sire $4=16 \%$; Sire $5=4 \%$, and Sire $6=$ $8 \%$ ). After removing all cows that lost pregnancy after day 30, pregnancies by sires classified as high embryonic loss had lower PAG compared to pregnancies by low embryonic loss sires $(8.5 \pm 0.35 v s$. $9.48 \pm 0.36 \mathrm{ng} / \mathrm{ml} ; \mathrm{P}=0.05)$. In summary, $\mathrm{PAG}$ concentration was driven by the ability of pregnancy maintenance and by sire used at TAI. Exploring this relationship might be interesting to improve sire fertility regarding late embryonic loss.

The overall conclusion is that pregnancy rates to timed artificial insemination is influenced by various factors. In this review, we proposed multiple strategies that could increase the fertility of Nelore cows.

Table 7. Overall pregnancy to timed artificial insemination (P/TAI) by AI center and variation by sire. Data used included multiparous cows with BCS at AI between 2.75 and 3.75 and sires with more than 100 AI.

\begin{tabular}{cccc}
\multicolumn{2}{c}{ included multiparous cows with BCS at AI between } & 2.75 and 3.75 and sires with more than 100 AI. \\
\hline AI center & Number of AI & P/TAI & $\begin{array}{c}\text { P/TAI } \\
\text { Range }\end{array}$ \\
& & $54.8 \%$ & 38.3 to $79.1 \%$ \\
A & 45,231 & $55.4 \%$ & 30.9 to $70.2 \%$ \\
B & 128,443 & $50.5 \%$ & 38.1 to $57.9 \%$ \\
C & 9,434 & $56.7 \%$ & 42.8 to $76.9 \%$ \\
D & 19,311 & $54.8 \%$ & 28.2 to $72.4 \%$ \\
E & 25,522 & $52.5 \%$ & 32.1 to $62.7 \%$ \\
F & 32,397 & $54.9 \%$ & 22.8 to $81.3 \%$ \\
G & 7,042 & &
\end{tabular}

Adapted from GERAR group.

\section{References}

Aono FH, Cooke RF, Alfieri AA, Vasconcelos JLM 2013. Effects of vaccination against reproductive diseases on reproductive performance of beef cows submitted to fixed-timed AI in Brazilian cow-calf operations. Theriogenology, 79:242-248.

Claro Junior I, Sa Filho OG, Peres RFG, Aono FHS, Day ML, Vasconcelos JLM. 2010. Reproductive performance of prepubertal Bos indicus heifers after progesterone-based treatments. Theriogenology, 74:903911.

Cooke RF, Bohnert DW, Meneghetti M, Losi TC, Vasconcelos JLM. 2011. Effects of temperament on pregnancy rates to fixed-timed AI in Bos indicus beef cows. Livest Sci 142:108-113.

Cooke RF. 2014. Temperament and acclimation to human handling influence growth, health, and reproductive responses in Bos taurus and B. indicus cattle. J Anim Sci, 92:5325:5333.

Cooke RF, Schubach KM, Marques RS, Peres RG, Silva LGT, Carvalho R, Cipriano RS, Bohnert DW, Pires AV, Vasconcelos JLM. 2017. Effects of temperament on physiological, productive, and reproductive responses in Bos indicus beef cows. $J$ Anim Sci, 95:1-8. doi: 10.2527/jas.2016.1098.

Costa WM, Carvalho ER, Pereira MHC, Peres RFG, Vasconcelos JLM. 2015. Supplementation with melengestrol acetate post TAI improves fertility in suckled Nelore cows. Anim Reprod, 12:660. (abstract).

Lopes CN, Scarpa AB, Cappellozza BI, Cooke RF, Vasconcelos JLM. 2009. Effects of rumen-protected polyunsaturated fatty acid supplementation on reproductive performance of Bos indicus beef cows. $J$ Anim Sci, 87:3935-3943.

Lopes CN, Cooke RF, Reis MM, Peres RFG, Vasconcelos JLM. 2011. Strategic supplementation of calcium salts of polyunsaturated fatty acids to enhance 
reproductive performance of Bos indicus beef cows. $J$ Anim Sci, 89:3116-3124.

Meneghetti M, Vasconcelos JLM . 2008. Mês de parição, condição corporal e resposta ao protocolo de inseminação artificial em tempo fixo em vacas de corte primíparas. Arq Bras Med Vet Zootec, 60:786-793.

Meneghetti M, Sá Filho OG, Peres RFG, Lamb GC, Vasconcelos JLM. 2009. Fixed-time artificial insemination with estradiol and progesterone for $B$. indicus cows I: Basis for development of protocols. Theriogenology, 72:179-189, 2009.

Peres RFG, Carvalho R, Graff H, Furlan Junior JH, Rodrigues ADP, Franco GA, Keisler DH, Smith MF, Pohler KG, Vasconcelos JLM. 2016. Corn supplementation during 41 days after the begginning of TAI protocol and its effects on metabolic hormones and reproductive performance of Nelore females, Anim Reprod, 13:382. (abstract).
Pohler KG, Peres RFG, Greeen JA, Graff H, Martins T, Vasconcelos JLM, Smith MF. 2016. Use of bovine pregnancy-associated glycoproteins to predict late embryonic mortality in postpartum Nelore beef cows. Theriogenology, 85:1652-1659.

Rodrigues ADP, Peres RFG ; Lemes AP, Martins T, Pereira MHC; Day ML, Vasconcelos JLM. 2013 Progesterone-based strategies to induce ovulation in prepubertal Nellore heifers.Theriogenology, 79:135-141.

Rodrigues ADP, Peres RFG, Lemes AP, Martins T, Pereira MHC, Carvalho ER, Day ML, Vasconcelos JLM. 2014. Effect of interval from induction of puberty to initiation of a timed AI protocol on pregnancy rate in Nellore heifers. Theriogenology. v.82:760-766.

Rodrigues ADP, Peres RFG, Day ML, Vasconcelos JLM. 2016. Effect of eCG and P4 level in timed AI programs in bos indicus and bos indicus $\mathrm{x}$ bos taurus heifers. J Dairy Sci, 99(E-suppl. 1):502. (abstract). 